\title{
Bir Üniversite Hastanesine Başvuran Jinekolojik ve Meme Kanserli Hastalarda Tamamlayıcı Sağlık Yaklaşımları Kullanımı*
}

\section{The Complementary Health Approaches Use with Gynecologic and Breast Cancer Patients Admitted to a}

University Hospital

\author{
Seda Kurt', Hatice Kahyaoğlu Sütii, Burcu Küçükkayaiii
}

' Dr. Öğr. Üyesi, Trakya Üniversitesi Sağlık Bilimleri Fakültesi Hemşirelik Bölümü Iç̧ Hastalıkları Hemşireliği Anabilim Dalı https://orcid.org/0000-0003-1844-1229

iiDoç. Dr., Trakya Üniversitesi Sağlık Bilimleri Fakültesi Hemşirelik Bölümü Kadın Sağlığı ve Hastalıkları Hemşireliği Anabilim Dalı https://orcid.org/0000-0001-8840-6846

iii'Arş. Gör., Trakya Üniversitesi Sağlık Bilimleri Fakültesi Hemşirelik Bölümü Kadın Sağlığı ve Hastalıkları Hemşireliği Anabilim Dalı https://orcid.org/0000-0002-3421-9794

Öz

Bu çalışmada, bir üniversite hastanesine başvuran jinekolojik ve meme kanserli hastalarda Tamamlayıcı Sağlık Yaklaşımları (TSY) kullanım durumlarının araştırılması amaçlanmıştır.

Kesitsel ve tanımlayıcı tipte olan bu araştırma Haziran-Ekim 2016 tarihleri arasında bir üniversitesi hastanesinde yürütülmüştür. Araştırmanın örneklemini 130 kadın hasta oluşturmuştur. Araştırma verileri, "Anket Formu" ile toplanmıştır.

Jinekolojik ve meme kanserli hastaların \%56,9'unun jinekolojik kanser ve \%43,1'inin meme kanseri olduğu belirlenmiştir. Jinekolojik kanserli hastaların \%32,4'ünün, meme kanserli hastaların \%37,5'inin tıbbi tedavi yöntemlerine ek olarak TSY kullandığı bulunmuştur. Resim ve el işi yapma gibi girişimleri jinekolojik kanserli hastaların daha fazla kullandığı ve meme kanserli hastaların arkadaşları ile daha fazla etkileşimde oldukları bulunmuştur. Jinekolojik kanserli hastaların daha fazla papatya ve ebegümeci otunu kullandığı belirlenmiştir. Omega ve anzer balını jinekolojik kanserli hastaların meme kanserli hastalara göre daha fazla kullandığı; meyve/sebze tüketiminin meme kanserli hastalarda jinekolojik kanserli hastalardan daha fazla olduğu tespit edilmiştir.

Sonuç olarak, jinekolojik kanserli hastaların daha fazla el becerilerine yönelik, meme kanserli hastaların daha çok sosyalleşmeye yönelik rahatlama girişimlerini kullandığı; jinekolojik kanserli hastaların daha çok bitkisel otlar, omega 3 ve anzer balı, meme kanserli hastaların meyve/sebze kullanımı gibi bitkisel ve besinsel yaklaşımları kullandığı söylenebilir.

Anahtar Kelimeler: Jinekolojik kanser, Meme Kanseri, Tamamlayıcı Sağlık Yaklaşımları

ABSTRACT

The aim of this study was to investigate the Complementary Health Approaches use with gynecological and breast cancer patients admitted to a university hospital.

This cross-sectional and descriptive study was conducted between June-October 2016 at a university hospital. The sample of the study consisted of 130 female patients. Research datas were collected with "Questionnaire Form".

It was determined that $56.9 \%$ of the patients had gynecological cancer and $43.1 \%$ had breast cancer. It was found that $32.4 \%$ of gynecological cancer patients and $37.5 \%$ of breast cancer patients used CHA in addition to medical treatment methods. It was found that gynecologic cancer patients used more painting and handcrafts and breast cancer patients interacted more with their friends. It was determined that the patients with gynecological cancer used more chamomile and hibiscus grass. Omega and anzer honey is used more by gynecological cancer patients than breast cancer patients; fruit/vegetable consumption was higher in breast cancer patients than in gynecological cancer patients.

As a result, it was said, gynecological cancer patients used more manual skills, breast cancer patients more relaxation attempts to socialize; gynecological cancer patients mostly herbal herbs, omega 3 and anzer honey, breast cancer patients use herbal and nutritional approaches such as the use of fruit/vegetables.

Keywords: Gynecologic Cancer, Breast Cancer, Complementary Health Approaches

*Lokman Hekim Dergisi, 2019; 9 (3): 326-336

DOI: $10.31020 /$ mutftd.589250

e-ISSN: $1309-8004$

Geliş Tarihi - Received: 9 Temmuz 2019; Kabul Tarihi - Accepted: 20 Ağustos 2019

iletişim - Correspondence Author: Seda Kurt <sedakurt81@gmail.com> 


\section{Giriş}

Amerika Birleşik Devletleri Ulusal Sağlık Enstitüsü’ne (NIH) bağlı Ulusal Tamamlayıcı ve İntegratif Sağlık Birimi (National Center for Complementary and Integrative Health (NCCIH-2016)) tarafından tamamlayıcı tıp, konvansiyonel tıp ile birlikte kullanılan olarak tanımlanmıştır. Alternatif tıp, konvansiyonel tıbbin yerine kullanılabilen; integratif tıp ise alternatif ve tamamlayıcı tıp ile kanıta dayalı tıp uygulamaları değerlendiren bütünleştirici/bütüncül tıp olarak belirtilmiştir. NCCIH bu tıp yaklaşımlarının tümünü "Tamamlayıcı Sağlık Yaklaşımları (TSY)" olarak kabul etmiştir. ${ }^{1}$ Günümüzde oldukça sık kullanılan "Tamamlayıcı Sağıık Yaklaşımları" zihin ve beden uygulamaları ile doğal ürünler şeklinde iki grupta sınıflandırılmıştır. Zihin ve beden uygulamaları; meditasyon, yoga, iyileştirici dokunma, masaj terapi, akupunktur, hareket terapileri, relaksasyon teknikleri, spinal manipülasyon, hipnoterapi, Tai chi ve qi gong gibi geleneksel çin uygulamalarıdır. Doğal ürünler olarak; bitkiler, çeşitli vitaminler, mineraller ve probiyotikler kullanılmaktadır. ${ }^{1,2}$ TSY, bitkilerden vitaminlere, masajdan akupunktur, müzik terapisi, hipnoz gibi rahatlama tekniklerine, dua ve telkin gibi geniş bir yelpazeyi kapsamaktadır. ${ }^{3}$ TSY en çok semptomları yönetmek, ilaçların yan etkilerini azaltmak, immün sistemi güçlendirmek amacıyla mevcut tıbbi tedaviyle birlikte kullanılmakta, bütünleştirici tıbbi anlayışı oluşturmaktadır. ${ }^{4}$ Dünya genelinde sıklıkla onkoloji hastalarında palyatif ve destekleyici bakımın önemli bir bölümünde kullanılmakla birlikte, kronik hastalıklar gibi farklı hasta popülasyonlarında da kullanılabilmektedir. ${ }^{5-7}$ Hastaların TSY kullanım nedenleri; jinekolojik sorunlar, arkadaş önerisi, daha iyi hissetme, kas-iskelet sorunları, nörolojik problemler vb. olarak bildirilmiştir. ${ }^{8}$ Onkoloji hastaları yaşamlarını tehdit eden bir hastalıkla yüz yüze kalmaları, tedavilerin genellikle çok uzun sürmesi ve umut vermemesi gibi nedenlerle TSY uygulamalarına başvurmaktadırlar. ${ }^{5,6}$ Bu bağlamda; kanser hastaları fiziksel ve emosyonel iyilik hali ve tedavi sağlamak ya da tedaviye destek olmak, tedavinin yan etkilerini azaltmak ve bu etkilerle baş etmek, kanserin tekrarlamasını önlemek, konvansiyonel tedaviler yerine kullanmak amacıyla ya da son çare olarak gördükleri için TSY uygulamalarına başvurmaktadır. ${ }^{5}$ Meme kanseri olan hastaların TSY yöntemlerini sık olarak kullandıkları, çoğunlukla da dua ve bitkisel yöntemleri tercih ettikleri bildirilmiştir. Tedavilerin yan etkilerinin azaltılması, emosyonel iyilik halinin devamı, daha uzun ve kaliteli yaşamak amacıyla hastaların tercih ettikleri belirtilmiştir. Hastaların TSY kullanımı ile ilgili sağlık çalışanlarına bilgi vermediği, kemoterapi, radyoterapi/ hormon tedavisi devam edenlerin büyük çoğunluğunun beraberinde TSY kullandığı belirlenmiştir. ${ }^{9}$ Ülkemizde jinekolojik kanserlerde TSY kullanımına ilişkin yapılan çalışmalara bakıldığında ise; çalışma sayısının yetersiz olması ile birlikte bu çalışmalarda TSY kullanımının yaygın olduğu görülmektedir. ${ }^{10}$ TSY kullanımı yaygın olmakla birlikte yapılan bu çalışmalarda hastalardan hiç birisi TSY yöntemine kendi bilgilerine dayanarak başvurmadıkları ve TSY yöntemine başvuran hastaların kullandıkları yöntemi doktor ve hemşireleriyle paylaşmadıkları saptanmıştır. ${ }^{11,12}$

Özellikle; yaşamlarını tehdit eden bir hastalıkla yüz yüze kalan kanserli hastaların tedaviyi sağlamak ya da tedavinin yan etkilerini azaltmak, kanserin tekrarlamasını önlemek gibi nedenlerle başvurdukları TSY uygulamalarına yönelik ilgilerinin artması sonucu sağlık bakım profesyonellerinin ve sağlık ekibi üyesi olarak hemşirelerin, tamamlayıcı terapilerde rol alması bir zorunluluk haline gelmiştir. ${ }^{12,13}$

Bu çalışma; bir üniversite hastanesine başvuran jinekolojik ve meme kanserli hastalarda Tamamlayıcı Sağlık Yaklaşımları (TSY) kullanım durumlarının araştııılması amacıyla planlanmıştır.

\section{GEREÇ VE YÖNTEM}

\section{Araştırmanın Tipi}

Bu araştırma; kesitsel tipte planlanmıştır.

\section{Araştırmanın Yeri ve Zamanı}

Bu araştırma Haziran-Ekim 2016 tarihleri arasında Trakya Üniversitesi Balkan Onkoloji Hastanesi Ayaktan Kemoterapi ve yatan hasta kliniklerinde yürütülmüştür.

\section{Araştırma Soruları}

1. Jinekolojik ve meme kanserli hastaların TSY kullanım durumları nedir?

2. Jinekolojik ve meme kanserli hastaların TSY kullanım durumları arasında farklııklar var mıdır? 


\section{Araştırmanın Evreni ve Örneklemi}

Araştırmanın evrenini; Haziran-Ekim 2016 tarihleri arasında Trakya Üniversitesi Balkan Onkoloji Hastanesi Ayaktan Kemoterapi ve yatan hasta kliniklerine başvuran, 18 yaş üstü, jinekolojik ve meme kanseri tanısı ile kemoterapi tedavisi gören/görmüş hastalar oluşturmuştur. Arştırmanın örneklemi; Uğurluel ve ark. (2007) çalışmasında TSY kullanım oranı \%44 olarak baz alınarak, \%5 yanılma payı ve $d=0,088$ tolerans değeriyle 122 kadın hastanın çalışmaya alınması gerektiği hesaplanmıştır. ${ }^{13}$ Olası kayıplar göz önüne alınarak 130 kadın hasta çalışmaya dahil edilmiştir.

\section{Veri Toplama Aracı}

Araştırma verileri; araştırmacılar tarafından literatür incelenerek hazırlanan anket formu ile elde edilmiştir. ${ }^{9,12,14}$

Anket formu: Anket formu; üç bölümden oluşmaktadır. 1. bölüm hastaların kişisel özellikleri (yaş, eğitim durumu, çalışma durumu, medeni durum, gelir durumu) içeren 5 soru; 2. bölüm hastalığa ve tedaviye ilişkin özellikleri (hastalığın tanısı, hastalığın durumu, tedavi türü vb.) içeren 5 soru; 3. bölüm TSY kullanımına yönelik (dans etme, masaj yaptırma, egzersiz yapma, ısırgan otu kullanma, ada çayı içme, sarımsak yeme vb.) 63 soru olmak üzere toplam 73 sorudan oluşmaktadır. ${ }^{9,12,14}$

\section{Verlerin İstatstistiksel Analizi}

Verilerin analizi SPSS 20,0 programı kullanılarak yapılmıştır. Hastaların sosyo-demografik verileri ve TSY kullanım durumları tanımlayıcı istatistikler kullanılarak (sayı ve \%); kategorik verilerin karşılaştırııması kikare testi ile değerlendirilmiştir. Tüm testlerde $p<0,05$ istatistiksel anlamlılık değeri kabul edilmiştir.

\section{Araştırmanın Etik Yönü}

Araştırma için Trakya Üniversitesi Bilimsel Araştırmalar Etik Kurulu'ndan 15/06/2016 tarihinde BAEK 2016/115 nolu etik onay alınmıştır. Çalışmaya katılan hastalara araştırmanın amacı açıklandıktan sonra anketlere kimlik bilgilerinin yazılmayacağı ve gizlilik ilkesine uyulacağı söylenerek sözel bilgilendirilmiş onamları alınmıştır. Anket formları yüzyüze görüşme yöntemi ile 10-15 dakikalık süre içerisinde uygulanmıştır.

\section{BULGULAR}

Jinekolojik ve meme kanserli hastaların ( $n=130$ ) yaş ortalaması $49,5 \pm 15,0$ olup $\% 86,2$ 'sinin evli, \%68,5'inin okuryazar veya ilköğretim mezunu, \%96,9'unun gelirinin gidere eşit, $\% 64,6$ 'sının ev hanımı olduğu belirlenmiştir (Tablo 1).

Tablo 1. Jinekolojik ve Meme Kanserli Hastaların Bazı Kişisel Özellikleri

\begin{tabular}{|c|c|c|}
\hline \multirow{3}{*}{ Yaş } & \multicolumn{2}{|c|}{ Ort $\pm S S$} \\
\hline & \multicolumn{2}{|c|}{$49,5 \pm 15,0$} \\
\hline & $\mathbf{n}$ & $\%$ \\
\hline \multicolumn{3}{|l|}{ Medeni Durum } \\
\hline Evli & 112 & 86,2 \\
\hline Bekar & 18 & 14,0 \\
\hline \multicolumn{3}{|l|}{ Eğitim Durumu } \\
\hline Okur-yazar değil & 6 & 4,6 \\
\hline Okur-yazar, Illköğretim & 89 & 68,5 \\
\hline Lise ve üzeri & 35 & 30,0 \\
\hline \multicolumn{3}{|l|}{ Gelir Düzeyi } \\
\hline Gelir giderden az & 2 & 1,5 \\
\hline Gelir gidere eşit & 126 & 96,9 \\
\hline Gelir giderden fazla & 2 & 1,5 \\
\hline \multicolumn{3}{|l|}{ Çalışma Durumu } \\
\hline Ev Hanımı & 84 & 64,6 \\
\hline Çalışıyor & 25 & 19,2 \\
\hline Emekli & 18 & 13,8 \\
\hline Diğer & 3 & 2,3 \\
\hline
\end{tabular}


Hastaların \%21,5'inin tanısı over , \%20'si endometrium, \%12,3'ü serviks, \%3,1'i vulva ( $n=74 / \% 56,9) ; \% 43,1^{\prime} i$ meme kanseri $(n=56)$ olup \%78,6'sının metastazının olmadığı belirlenmiştir. Hastaların \%56,9'unun kemoterapi ve radyoterapi tedavisi gördüğü, $\% 93,8^{\prime}$ inin cerrahi tedavi olduğu saptanmıştır. Hastaların \%34,6'sı tıbbi tedaviye ek olarak TSY kullandığını ifade etmiştir (Tablo 2).

Tablo 2. Jinekolojik ve Meme Kanserli Hastaların Tedaviye Illişkin Özellikleri

\begin{tabular}{|c|c|c|}
\hline & $\mathbf{n}$ & $\%$ \\
\hline \multicolumn{3}{|l|}{ Kanser Tipi } \\
\hline Over & 28 & 21,5 \\
\hline Endometrium & 26 & 20,0 \\
\hline Serviks & 16 & 12,3 \\
\hline Vulva & 4 & 3,1 \\
\hline Meme & 56 & 43,1 \\
\hline \multicolumn{3}{|l|}{ Hastalığın Durumu } \\
\hline Primer (Metastazı yok) & 99 & 78,6 \\
\hline Metastatik & 27 & 21,4 \\
\hline \multicolumn{3}{|l|}{ Alınan Tıbbi Tedavi } \\
\hline Kemoterapi (KT) & 28 & 21,5 \\
\hline Radyoterapi (RT) & 4 & 3,1 \\
\hline $\mathrm{KT}+\mathrm{RT}$ & 74 & 56,9 \\
\hline Tedavi almadı & 24 & 18,5 \\
\hline $\begin{array}{l}\text { Cerrahi Tedavi Olma Durumu } \\
\text { Hayır }\end{array}$ & 8 & 6,2 \\
\hline Evet & 122 & 93,8 \\
\hline $\begin{array}{l}\text { Tıbbi tedavi yöntemine ek olarak TSY kullanma durumu } \\
\text { Hayır }\end{array}$ & 85 & 65,4 \\
\hline Evet & 45 & 34,6 \\
\hline
\end{tabular}

Hem jinekolojik hem de meme kanseri olan hastaların TSY kullanımına başvurma durumlarının benzer olduğu saptanmıştır ( $p>0,05)$. Hastaların TSY kullanımına en çok ümit verici olumlu düşünmeyi sağladığı için başvurdukları ve bilgi edindikleri yerlerin (arkadaş, hekim, aktar, internet vb.) benzer özellikte olduğu belirlenmiştir ( $p>0,05)$. Jinekolojik kanserli hastaların \%20,8'inin, meme kanserli hastaların \%29,6'sının TSY kullanımına doktorlarına danışarak başladıkları tespit edilmiştir. Jinekolojik kanserli hastaların (\%20) TSY kullandığını, meme kanserli hastalara göre $(\% 8,3)$ daha fazla hemşirelerle paylaştığı ancak aralarında anlamlı farkın olmadığı ve hemşire ile paylaşımın oldukça düşük olduğu saptanmıştır $(p=0,226)$. Jinekolojik ve meme kanserli hastaların çoğunun, TSY hakkında bilgiyi arkadaşlarından $(\% 75,0 / \% 50,0)$, aktardan $(\% 50,0 / \% 34,6)$ ve internetten (\%33,3/\%42,3) edindiği bulunmuştur (Tablo 3).

TSY kullandığını ve kullanmadığını ifade eden hastaların, tamamlayıcı yaklaşımlardan rahatlamak için yaptıkları girişimler ayrı ayrı incelendiğinde; resim yapma ve el işi yapma gibi girişimleri jinekolojik kanserli hastaların $(\% 37,5)$, meme kanserli hastalara göre $(\% 7,7)$ daha fazla kullandığı $(p=0,013)$ ve meme kanserli hastaların $(\% 57,7)$ jinekolojik kanserli hastalara göre (\%25) arkadaşları ile daha fazla etkileşimde oldukları $(p=0,019)$ bulunmuştur (Tablo 4). 
Tablo 3. Jinekolojik ve Meme Kanserli Hastaların TSY Kullanım Dağılımının Karşılaştırılması

\begin{tabular}{|c|c|c|c|c|c|}
\hline & \multicolumn{2}{|c|}{$\begin{array}{l}\text { Jinekolojik } \\
\text { Kanserler }\end{array}$} & \multicolumn{2}{|c|}{ Meme Kanseri } & \multirow[t]{2}{*}{$\mathbf{p}$} \\
\hline & $\mathbf{n}$ & $\%$ & $\mathbf{n}$ & $\%$ & \\
\hline \multicolumn{6}{|l|}{ TSY Kullanımına Neden Olan Faktörler } \\
\hline Hastalıkla savaşmak & 2 & 8,3 & 1 & 4,5 & \multirow{8}{*}{0,170} \\
\hline Kanserle savaşa karşı vücudun direncini artırmak & - & - & 4 & 18,2 & \\
\hline Fiziksel görünümü düzeltmek & 2 & 8,3 & - & - & \\
\hline Duygusal iyileşme sağlamak & - & - & 1 & 4,5 & \\
\hline Ümit verici olumlu düşünmek & 16 & 66,7 & 11 & 50,0 & \\
\hline Acı duymamak & - & - & 1 & 4,5 & \\
\hline Hastalığın yan etkilerini azaltmak & 4 & 16,7 & 3 & 13,6 & \\
\hline Kararsız & - & - & 1 & 4,5 & \\
\hline \multicolumn{6}{|l|}{ TSY Yönteminin Tıbbi Tedavi Kadar Etkili Olma Durumu } \\
\hline Hayır & 13 & 54,2 & 8 & 36,4 & \multirow{3}{*}{0,086} \\
\hline Evet & 1 & 4,2 & 6 & 27,3 & \\
\hline Bilmiyorum & 10 & 41,7 & 8 & 36,4 & \\
\hline \multicolumn{6}{|l|}{ Kullanılan TSY ile ilgili hekime danışma durumu } \\
\hline Hayır & 19 & 79,2 & 19 & 70,4 & \multirow[b]{2}{*}{0,347} \\
\hline Evet & 5 & 20,8 & 8 & 29,6 & \\
\hline \multicolumn{6}{|l|}{ Kullanılan TSY hemşire ile paylaşma durumu } \\
\hline Hayır & 20 & 80,0 & 22 & 91,7 & \multirow{2}{*}{0,226} \\
\hline Evet & 5 & 20,0 & 2 & 8,3 & \\
\hline \multirow{2}{*}{\multicolumn{6}{|c|}{$\begin{array}{l}\text { Kullanılan TSY ile ilgili bilgi edinme yeri } \\
\text { Arkadaslarımdan }\end{array}$}} \\
\hline & & & & & \\
\hline Hayır & 6 & 25,0 & 13 & 50,0 & \multirow{2}{*}{0,063} \\
\hline Evet & 18 & 75,0 & 13 & 50,0 & \\
\hline \multicolumn{6}{|l|}{ Hekimden } \\
\hline Hayır & 21 & 87,5 & 23 & 88,5 & \multirow{2}{*}{0,627} \\
\hline Evet & 3 & 12,5 & 3 & 11,5 & \\
\hline \multicolumn{6}{|l|}{ Aktardan } \\
\hline Hayır & 12 & 50,0 & 17 & 65,4 & \multirow{2}{*}{0,208} \\
\hline Evet & 12 & 50,0 & 9 & 34,6 & \\
\hline \multicolumn{6}{|l|}{ internetten } \\
\hline Hayır & 16 & 66,7 & 15 & 57,7 & \multirow{2}{*}{0,359} \\
\hline Evet & 8 & 33,3 & 11 & 42,3 & \\
\hline \multicolumn{6}{|l|}{ Aile } \\
\hline Hayır & 16 & 66,7 & 17 & 65,4 & \multirow{2}{*}{0,581} \\
\hline Evet & 8 & 33,3 & 9 & 34,6 & \\
\hline \multicolumn{6}{|l|}{ Hastalar } \\
\hline Hayır & 22 & 91,7 & 21 & 80,8 & \multirow{2}{*}{0,244} \\
\hline Evet & 2 & 8,3 & 5 & 19,2 & \\
\hline \multicolumn{6}{|l|}{ Gazete/Televizyon } \\
\hline Hayır & 16 & 66,7 & 14 & 53,8 & \multirow{2}{*}{0,263} \\
\hline Evet & 8 & 33,3 & 12 & 46,2 & \\
\hline
\end{tabular}

*Birden fazla seçenek işaretlenmiştir. 
Tablo 4. Jinekolojik İle Meme Kanserli Hastaların Tamamlayıcı Yaklaşımlardan Rahatlamak İçin Yaptıkları Girişimlerin Dağılımının Karşılaştırılması

\begin{tabular}{|c|c|c|c|c|c|}
\hline & \multicolumn{2}{|c|}{ Jinekolojik Kanserler } & \multicolumn{2}{|c|}{ Meme Kanseri } & \multirow[t]{2}{*}{$\mathbf{p}$} \\
\hline & $\mathrm{n}$ & $\%$ & $\mathrm{n}$ & $\%$ & \\
\hline \multicolumn{6}{|c|}{ Dans ederim } \\
\hline Hayır & 10 & 41,7 & 16 & 61,5 & 0,131 \\
\hline Evet & 14 & 58,3 & 10 & 38,5 & \\
\hline \multicolumn{6}{|l|}{ Gülerim } \\
\hline Hayır & 7 & 29,2 & 10 & 38,5 & 0,347 \\
\hline Evet & 17 & 70,8 & 16 & 61,5 & \\
\hline \multicolumn{6}{|c|}{ Resim yaparım, el-işi yaparım } \\
\hline Hayır & 15 & 62,5 & 24 & 92,3 & 0,013 \\
\hline Evet & 9 & 37,5 & 2 & 7,7 & \\
\hline \multicolumn{6}{|c|}{ Yoga/ Pilates yaparım } \\
\hline Hayır & 22 & 91,7 & 25 & 96,2 & 0,469 \\
\hline Evet & 2 & 8,3 & 1 & 3,8 & \\
\hline \multicolumn{6}{|c|}{ Meditasyon yaparım } \\
\hline Hayır & 23 & 95,9 & 24 & 92,3 & 0,511 \\
\hline Evet & 1 & 4,2 & 2 & 7,7 & \\
\hline \multicolumn{6}{|c|}{ Dua ederim } \\
\hline Hayır & - & - & 1 & 3,8 & 0,520 \\
\hline Evet & 24 & 100,0 & 25 & 96,2 & \\
\hline \multicolumn{6}{|c|}{ Vücut masajı yaptırırım } \\
\hline Hayır & 19 & 79,2 & 19 & 73,1 & 0,433 \\
\hline Evet & 5 & 20,8 & 7 & 26,9 & \\
\hline \multicolumn{6}{|c|}{ Ayak masajı yaptırırım } \\
\hline Hayır & 19 & 79,2 & 20 & 76,9 & 0,560 \\
\hline Evet & 5 & 20,8 & 6 & 23,1 & \\
\hline \multicolumn{6}{|c|}{ Akupunktur yaptırırım } \\
\hline Hayır & 23 & 95,8 & 25 & 96,2 & 0,735 \\
\hline Evet & 1 & 4,2 & 1 & 3,8 & \\
\hline \multicolumn{6}{|c|}{ Egzersiz yaparım } \\
\hline Hayır & 6 & 25,0 & 10 & 38,5 & 0,238 \\
\hline Evet & 18 & 75,0 & 16 & 61,5 & \\
\hline \multicolumn{6}{|c|}{ Arkadaşlarımla görüşürüm } \\
\hline Hayır & 18 & 75,0 & 11 & 42,3 & 0,019 \\
\hline Evet & 6 & 25,0 & 15 & 57,7 & \\
\hline \multicolumn{6}{|c|}{ Reiki yaparım } \\
\hline Hayır & 23 & 95,8 & 25 & 96,2 & 0,735 \\
\hline Evet & 1 & 4,2 & 1 & 3,8 & \\
\hline
\end{tabular}

*Birden fazla seçenek işaretlenmiştir.

TSY kullandığını ve kullanmadığını ifade eden hastaların, hastalık tanısının konması ile beraberinde bitkisel ve besinsel yaklaşımları kullanım durumlarına ayrı ayrı bakıldığında; jinekolojik kanserli hastaların (\%58,3), meme kanserli hastalara göre $(\% 19,2)$ daha fazla papatya kullandığı $(p=0,005)$; ebegümeci otunu jinekolojik kanserli hastaların \%16,7'sinin kullandığı ve meme kanserli hastaların kullanmadığı (\%0) belirlenmiştir $(p=0,046)$. Omega $3^{\prime} u ̈$ jinekolojik kanserli hastaların $(\% 54,2)$ meme kanserli hastalara göre $(\% 26,9)$ daha fazla kullandığı $(\mathrm{p}=0,046)$; anzer balını jinekolojik kanserli hastaların $(\% 70,8)$ meme kanserli hastalara göre $(\% 30,8)$ daha fazla kullandığ $(p=0,005)$; havucu meme kanserli hastaların $(\% 38,5)$ jinekolojk kanserli hastalardan $(\% 12,5)$ daha fazla kullandığı $(p=0,037)$; meyve / sebze tüketiminin meme kanserli hastalarda $(\% 65,4 / \% 65,4)$ jinekolojk kanserli hastalardan $(\% 29,2 / \% 25,0)$ daha fazla olduğu $(p=0,011 ; p=0,005)$ tespit edilmiştir (Tablo 5). 
Tablo 5. Jinekolojik ve Meme Kanserli Hastaların Bitkisel ve Besinsel Yaklaşımlar Kullanımına illişkin Dağılımın Karşılaştırılması

\begin{tabular}{|c|c|c|c|c|c|}
\hline & \multicolumn{2}{|c|}{ Jinekolojik Kanserler } & \multicolumn{2}{|c|}{ Meme Kanseri } & \multirow[t]{2}{*}{$p$} \\
\hline & $\mathbf{n}$ & $\%$ & $\mathbf{n}$ & $\%$ & \\
\hline \multicolumn{6}{|c|}{ Isırgan otu } \\
\hline Hayır & 20 & 83,3 & 22 & 84,6 & \multirow{2}{*}{0,601} \\
\hline Evet & 4 & 16,7 & 4 & 15,4 & \\
\hline \multicolumn{6}{|c|}{ Çörek otu } \\
\hline Hayır & 21 & 87,5 & 20 & 76,9 & \multirow{2}{*}{0,275} \\
\hline Evet & 3 & 12,5 & 6 & 23,1 & \\
\hline \multicolumn{6}{|l|}{ Kekik } \\
\hline Hayır & 17 & 0,8 & 23 & 88,5 & \multirow{2}{*}{0,114} \\
\hline Evet & 7 & 29,2 & 3 & 11,5 & \\
\hline \multicolumn{6}{|l|}{ Papatya } \\
\hline Hayır & 10 & 41,7 & 21 & 80,8 & \multirow{2}{*}{0,005} \\
\hline Evet & 14 & 58,3 & 5 & 19,2 & \\
\hline \multicolumn{6}{|c|}{ Ardıç otu } \\
\hline Hayır & 20 & 83,3 & 25 & 96,2 & \multirow{2}{*}{0,150} \\
\hline Evet & 4 & 16,7 & 1 & 3,8 & \\
\hline \multicolumn{6}{|c|}{ Ebegümeci } \\
\hline Hayır & 20 & 83,3 & 26 & 100,0 & \multirow{2}{*}{0,046} \\
\hline Evet & 4 & 16,7 & 0 & 0,0 & \\
\hline \multicolumn{6}{|l|}{ Zencefil } \\
\hline Hayır & 17 & 70,8 & 23 & 88,5 & \multirow{2}{*}{0,114} \\
\hline Evet & 7 & 29,2 & 3 & 11,5 & \\
\hline Zerdecal & & & & & \\
\hline Hayır & 20 & 83,3 & 24 & 96,0 & \\
\hline Evet & 4 & 16,7 & 1 & 4,0 & 0,162 \\
\hline Yeşil Çay & & & & & \\
\hline Hayır & 16 & 66,7 & 16 & 61,5 & \\
\hline Evet & 8 & 33,3 & 10 & 38,5 & 0,468 \\
\hline Ada Çay & & & & & \\
\hline Hayır & 17 & 70,8 & 19 & 73,1 & \\
\hline Evet & 7 & 29,2 & 7 & 26,9 & 0,554 \\
\hline Ihlamur & & & & & \\
\hline Hayır & 9 & 37,5 & 11 & 42,3 & 0477 \\
\hline Evet & 15 & 62,5 & 15 & 57,7 & $0,4 / 7$ \\
\hline Kuşburn & & & & & \\
\hline Hayır & 14 & 58,3 & 20 & 76,9 & \\
\hline Evet & 10 & 41,7 & 6 & 23,1 & 0,135 \\
\hline Ginseng & & & & & \\
\hline Hayır & 24 & 100,0 & 25 & 96,2 & م 52 \\
\hline Evet & - & - & 1 & 3,8 & $0,3<0$ \\
\hline Omega & & & & & \\
\hline Hayır & 11 & 45,8 & 19 & 73,1 & \\
\hline Evet & 13 & 54,2 & 7 & 26,9 & 0,046 \\
\hline Vitamin & & & & & \\
\hline Hayır & 16 & 66,7 & 22 & 84,6 & \\
\hline Evet & 8 & 33,3 & 4 & 15,4 & 0,124 \\
\hline Anzer $B$ & & & & & \\
\hline Hayır & 7 & 29,2 & 18 & 69,2 & \\
\hline Evet & 17 & 70,8 & 8 & 30,8 & 0,005 \\
\hline Karadut & & & & & \\
\hline Hayır & 12 & 50,0 & 16 & 61,5 & \\
\hline Evet & 12 & 50,0 & 10 & 38,5 & 0,296 \\
\hline Keçiboyı & & & & & \\
\hline Hayır & 8 & 33,3 & 15 & 57,7 & \\
\hline Evet & 16 & 66,7 & 11 & 42,3 & $0,0 / 4$ \\
\hline Greyfurt & & & & & \\
\hline Hayır & 20 & 83,3 & 19 & 73,1 & \\
\hline Evet & 4 & 16,7 & 7 & 26,9 & $0, \angle 98$ \\
\hline
\end{tabular}




\begin{tabular}{|c|c|c|c|c|c|}
\hline Sarımsak & 19 & 79,2 & 16 & 61,5 & 0,147 \\
\hline \multicolumn{6}{|l|}{ Hayır } \\
\hline Evet & 5 & 20,8 & 10 & 38,5 & \\
\hline \multicolumn{6}{|l|}{ Havuç } \\
\hline Hayır & 21 & 87,5 & 16 & 61,5 & \multirow{2}{*}{0,037} \\
\hline Evet & 3 & 12,5 & 10 & 38,5 & \\
\hline \multicolumn{6}{|l|}{ Meyveler } \\
\hline Hayır & 17 & 70,8 & 9 & 34,6 & \multirow{2}{*}{0,011} \\
\hline Evet & 7 & 29,2 & 17 & 65,4 & \\
\hline \multicolumn{6}{|l|}{ Sebzeler } \\
\hline Hayır & 18 & 75,0 & 9 & 34,6 & \multirow{2}{*}{0,005} \\
\hline Evet & 6 & 25,0 & 17 & 65,4 & \\
\hline \multicolumn{6}{|l|}{ Kırmızı et } \\
\hline Hayır & 11 & 45,8 & 10 & 38,5 & \multirow{2}{*}{0,405} \\
\hline Evet & 13 & 54,2 & 16 & 61,5 & \\
\hline \multicolumn{6}{|l|}{ Balık eti } \\
\hline Hayır & 8 & 33,3 & 10 & 37,0 & \multirow{2}{*}{0,508} \\
\hline Evet & 16 & 66,7 & 17 & 63,0 & \\
\hline \multicolumn{6}{|l|}{ Tavuk eti } \\
\hline Hayır & 17 & 70,8 & 13 & 48,1 & \multirow{2}{*}{0,087} \\
\hline Evet & 7 & 29,2 & 14 & 51,9 & \\
\hline \multicolumn{6}{|c|}{ Ekmek ve hamur işleri } \\
\hline Hayır & 16 & 66,7 & 15 & 55,6 & \multirow{2}{*}{0,301} \\
\hline Evet & 8 & 33,3 & 12 & 44,4 & \\
\hline \multicolumn{6}{|c|}{ Süt ve süt ürünleri } \\
\hline Hayır & 15 & 62,5 & 10 & 40,0 & \multirow{2}{*}{0,098} \\
\hline Evet & 9 & 37,5 & 15 & 60,0 & \\
\hline
\end{tabular}

\section{TARTIŞMA}

Onkoloji hastalarının yaşamlarını tehdit eden bir hastalıkla yüz yüze kalmaları nedeniyle hem tedaviyi sağlamak hem de tedavinin yan etkilerini azaltmak için başvurdukları TSY uygulamalarını kullanımına yönelik bilgilerinin ve yanlış uygulamalarının bilinmesi tedavinin etkinliği açısından çok önemlidir. ${ }^{12,14,15}$ Jinekolojik ve meme kanserli hastaların TSY kullanım durumlarının araştırılması amacıyla yürütülen bu çalışmadan elde edilen bulgular ulusal ve uluslararası literatür ile tartışılmışır.

Çalışmada, jinekolojik ve meme kanserli hastaların \%34,6'sının tıbbi tedaviye ek olarak TSY kullandığı bulunmuştur. Duman ve ark.'nın jinekolojik kanserli Türk kadınlarının dini ve geleneksel uygulamalarını inceledikleri çalışmada, jinekolojik kanserli hastaların \%86,2'sinin geleneksel ve dini uygulamalar yaptığı tespit edilmiştir. ${ }^{12}$ Yeşil ve ark.'nın çalışmasında, meme kanserli hastaların TSY kullanımının \%85,7 olduğu saptanmıştır. TSY kullanan hastaların \%44.3'ü tanı aldıktan hemen sonra tedavi süreci başlamadan bu yöntemlere başvurduğunu ifade ederken, \%35.7'si ise halen kanser tedavisi devam ederken TSY'a başvurduğunu belirtmiştir. ${ }^{9}$ Öztürk ve ark. jinekolojik kanserli hastaların TSY kullanımını \%28,0 olarak belirlenmiştir. ${ }^{16}$ Nazik ve ark.'nın Türkiye'de jinekolojik onkoloji hastalarının tamamlayıcı ve alternatif tıp kullanımını inceledikleri çalışmalarında, jinekolojik kanserli hastaların \%61,2'sinin TSY kullandığı saptanmıştır. ${ }^{17}$ Yavuz ve ark.'nın meme kanserli hastaların tamamlayıcı ve alternatif tedavi yöntemlerini kullanma durumlarını inceledikleri çalışmalarında, meme kanserli kadınların \%87'sinin TSY yöntemi kullandığını bulmuştur. ${ }^{18}$ Zeller ve ark., kanser tedavisi alan jinekolojik kanserli kadınların \%48'inin TSY yöntemi kullandığı belirlenmiştir. ${ }^{19}$ Molassiotis ve ark., Avrupa'da jinekolojik kanseri olan hastaların $\% 40,3^{\prime}$ ünün TSY kullandığını saptamıştır. ${ }^{20}$ Literatür ile çalışmadan elde ettiğimiz sonuca göre jinekolojik ve meme kanserli hastaların çoğunluğu tıbbi tedavinin yanında TSY kullanmaktadır. Bunun nedeninin; tıbbi tedavilerin yan etkilerinin azaltılması, psikolojik rahatlama sağlanması, uzun ve sağlıkı bir yaşama kavuşma ümidi ile olduğu düşünülmektedir.

Çalışmada, jinekolojik $(\% 66,7 / \% 16,7 / \% 8,3)$ ve meme kanserli $(\% 50,0 / 13,6 / 4,5)$ hastaların TSY en çok ümit verici olumlu düşünmeyi sağladığı/hastalığın yan etkilerinin azalmasını istediği/hastalıkla savaşmak için kullandığı bulunmuştur. Ayrıca meme kanserli hastaların kanserle savaşa karşı vücudun direncini artırmak $(\% 18,2)$ amacıyla TSY kullandığı saptanmıştır. Öztürk ve ark.'nın yaptıkları çalışmada, jinekolojik kanserli 
hastaların \%34,3'ünün vücudun direncini arttırmak, \%23,9'unun hastalıkla direkt savaş, \%13,4'ünün hastalık etkilerini azaltmak, $\% 7,5^{\prime}$ inin duygusal iyileşmeyi sağlamak ve $\% 6^{\prime}$ sının ümit ve olumlu düşünmeyi sağlamak amacıyla TSY kullandıkları belirlenmiştir. ${ }^{16}$ Nazik ve ark.'nın çalışmalarında, jinekolojik kanserli hastaların \%7,5'inin bağışıklık sistemini güçlendirmek, \%9'unun kanser tedavisi ile ilişkili semptomları hafifletmek, $\% 24,4$ 'ünün fiziksel ve duygusal iyilik elde etmek ve \%48,8'inin kanseri tedavi etmek amacıyla TSY kullandığı saptanmıştır. ${ }^{17}$ Molassiotis ve ark., TSY kullanımının temel nedenleri olarak; \%58.6'sının bedenin kansere karşı mücadele yeteneğini arttırmak, \%51,2'sinin fiziksel iyilik halini iyileştirmek ve \%48,3'ünün duygusal iyilik ve iyimserliği geliştirmek olduğu belirlenirken hastaların neredeyse \%60'ı TSY kullanmanın ilk nedeninin, vücudun kansere karşı savaşma kabiliyetini arttırmak olduğunu bildirdiğini saptamıştır. ${ }^{20}$ Sonuç olarak, hem literatür bulguları hem de çalışma bulguları benzer olup, jinekolojik ve meme kanserli hastaların çoğu ümit verici olumlu düşünmeyi sağlamak, hastalığın yan etkilerinin azaltmak ve hastalıkla savaşmak için TSY kullanmaktadır. Jinekolojik ve meme kanserli hastaların sağlıklı ve uzun bir yaşam ümidi ile TSY başvurduğu söylenebilir.

Çalışmada, jinekolojik ve meme kanserli hastaların çoğunun, TSY hakkında bilgiyi arkadaşlarından $(\% 75,0 / \% 50,0)$, aktardan $(\% 50,0 / \% 34,6)$ ve internetten $(\% 33,3 / \% 42,3)$ edindiği bulunmuştur. Duman ve ark.'nın yaptıkları çalışmada, jinekolojik kanserli hastaların \%59,5'inin çevreden (aile, arkadaş, komşu), \%31,9'unun televizyondan ve internetten, \%6,0'ının kitaptan ve gazeteden TSY yöntemleri hakkında bilgi aldığı tespit edilmiştir. ${ }^{12}$ Öztürk ve ark.'nın yaptıkları çalışmada, jinekolojik kanserli hastaların \%45,4'ünün televizyondan ve internetten, \%32,9'unun çevreden (aile, arkadaş, komşu) ve \%15,5'inin kitaptan ve gazeteden TSY yöntemleri hakkında bilgi aldığı belirlenmiştir. ${ }^{16}$ Nazik ve ark.'nın çalışmalarında, jinekolojik kanserli hastaların \%34,1'inin arkadaşlarından, \%31,7'sinin aile üyelerinden, \%17,1'inin kendilerinden, \%14,6'sının medya ve internetten ve \%2,4'ünün sağlık profesyonellerinden TSY hakkında bilgi aldığı saptanmıştır. ${ }^{17}$ Yavuz ve ark.'nın çalışmalarında, meme kanserli kadınların \%46,8'inin medyadan (televizyon, gazete, dergi vb.), \%25,8'inin akraba, komşu, arkadaş gibi tanıdıklarından, \%13,7'sinin başka bir meme kanserli kişiden TSY yöntemi hakkında bilgi aldığını bulmuştur. ${ }^{18}$ Molassiotis ve ark., jinekolojik kanserli hastaların TSY ile ilgili temel bilgi kaynağı olarak; \%55,2'sinin arkadaşları, \%27,6'sının aile, \%24,1'inin gazete, dergi veya TV gibi medya, $\% 17,2^{\prime}$ sinin hekimler, $\% 10,3$ 'ünün internet, $\% 10,3^{\prime}$ ünün TSY uygulayıcıları ve $\% 6,9$ 'unun hemşireler olduğunu saptamıştır. ${ }^{20}$ Literatür bulguları ile çalışma bulguları birbirine benzerlik göstermiş olup, jinekolojik ve meme kanserli hastaların TSY hakkında bilgiyi çeşitli kaynaklardan (arkadaş, aktar, internet vb.) aldıkları belirlenmiştir.

Çalışmada, jinekolojik kanserli hastaların \%20,8'inin, meme kanserli hastaların \%29,6'sının TSY kullanımına doktorlarına danışarak başladıkları belirlenmiştir. Jinekolojik kanserli hastaların \%20,0'sinin, meme kanserli hastaların \%8,3'ünün TSY kullandığını hemşirelerle paylaştığı tespit edilmiştir. Özellikle meme kanserli hastaların TSY kullandığını hemşire ile paylaşma oranının oldukça düşük olduğu saptanmıştır. Yeşil ve ark.'nın, yaptıkları çalışmada, meme kanserli hastaların \%65'inin doktoru ile paylaşmadığı saptanmıştır. ${ }^{19}$ Öztürk ve ark.'nın yaptıkları çalışmada, jinekolojik kanserli hastaların $\% 65,6$ 'sının doktoru veya hemşiresi ile paylaşmadığı belirlenmiştir. ${ }^{20}$ Düzen ve Korkmaz çalışmalarında, hastaların \%63,6'sının doktoru ve $\% 81,8^{\prime}$ inin hemşiresi ile paylaşmadığını bulmuştur. ${ }^{9}$ Nazik ve ark.'nın çalışmalarında, jinekolojik kanserli hastaların \%56,1'inin TSY kullandığını hemşiresi ile paylaştığı saptanmıştır. ${ }^{17}$ Yavuz ve ark.'nın çalışmalarında, meme kanserli kadınların \%19,5'inin doktoruna TSY kullandığını bildirdiğini belirlemiştir. ${ }^{18}$ Çalışma ve literatür sonuçları benzer nitelikte olup, jinekolojik ve meme kanserli hastaların çoğunluğu TSY kullanımını hekime danışmadan kullanmakta ve hemşireler ile paylaşmamaktadır. Tıbbi tedavi sürecinde kullanılan TSY'nın, kullanılan ilaçlarla etkileşime geçerek yan etkileri arttırabileceği, tedavi sürecine ve hastaya zarar verebileceğine yönelik bilgiler tıbbi tedaviye başlanmadan hastalar ile paylaşılması gerekmektedir. Tedavi sürecinde hemşire ve doktor tarafından TSY kullanım durumuna ilişkin aralıkı sorgulama yapılması gerektiği de düşünülmektedir.

Çalışmada, jinekolojik kanserli hastaların rahatlama girişimleri olarak en çok resim ve el işi yapmayı tercih ettiği, meme kanserli hastaların ise arkadaşları ile daha fazla etkileşimde oldukları belirlenmiştir. Bitkisel/besinsel yaklaşım olarak jinekolojik kanserli hastaların papatya, ebegümeci, omega 3, anzer balını tüketme durumlarının daha fazla olduğu ve meme kanserli hastaların havuç ve meyve/sebze tüketim durumlarının daha fazla olduğu bulunmuştur. Duman ve ark.'nın yaptıkları çalışmada, jinekolojik kanserli 
hastaların sırasıyla en çok namaz kıldığı, kutsal su içtiği, muska gibi takılar kullandığı, türbeleri ziyaret ettiği ve bitkisel yöntemler kullandığı tespit edilmiştir. ${ }^{12}$ Yeşil ve ark.'nın, yaptıkları çalışmada, meme kanserli hastaların rahatlamak için en çok dua ettiği, yoga, meditasyon, akupunktur, türbe ziyareti yaptığı; bitkisel girişim olarak çörek otu, ısırgan otu, yeşil çay kullandığı saptanmıştır. ${ }^{9}$ Öztürk ve ark.'nın yaptıkları çalışmada, jinekolojik kanserli hastaların en çok bitkisel yöntemlerden yararlandığı, vitamin ve mineral aldığı; bitkisel tedavi kullananların adaçayı, kuşburnu, nane, yeşil çay ve çörek otu kullandığı belirlenmiştir. ${ }^{16}$ Nazik ve ark.'nın çalışmalarında, jinekolojik kanserli hastaların sırasıyla bitkisel terapi, dua, beslenme rejimi, psikolojik terapi, masaj terapisi, rahatlama terapileri kullandığı saptanmıştır. ${ }^{17}$ Yavuz ve ark.'nın çalışmalarında, meme kanserli kadınların \%62'sinin metabolik/beslenme TSY kullandığı, bu yöntemleri kullananların sarımsak, ısırgan otu, vitamin keten tohumu kullandığı, ayrıca \%15'inin çesitli bitkisel/ metabolik TSY kullandığı (eşek sütü, defne yaprağı, kaplumbağa kanı, kırk kilit otu, isveç şurubu, civan perçemi, radika, turp otu, çörek otu, badem, ardıç tohumu, kantoron, papatya, kefir vb.), spor yaptığı ve namaz kıldığı/dua ettiği belirlenmiştir. ${ }^{18}$ Zeller ve ark.'nın çalışmalarında, jinekolojik kanserli kadınların antioksidan (vitamin) ile Çin bitkileri ve çaylarını kullandığı belirlenmiştir. ${ }^{19}$ Molassiotis ve ark., jinekolojik kanser teşhisi sonrası en sık kullanılan TSY; bitkisel ilaçlar, gevşeme teknikleri, vitaminler/mineraller, masaj, tıbbi çaylar ve refleksoloji girişimleri olduğunu saptamıştır. ${ }^{20}$ TSY ilişkin çalışma sonuçları ile literatür sonuçları farklılık göstermiş olup, bu farklılık çalışma yapılan örneklemin kişisel ve kültürel özellikleri, çalışmanın yapıldığı yer, TSY hakkında bilgi durumlarından kaynaklandığı söylenebilir. Aynı zamanda çalışmamızda; jinekolojik kanserli hastaların resim yapma ve el işi yapma gibi tek kişilik aktivitelerde bulunurken, meme kanserli hastaların ise arkadaşları ile daha fazla etkileşimde oldukları daha sosyal ortamları tercih ettikleri bulunmuştur.

\section{SONUÇ}

Jinekolojik ve meme kanserli hastalar TSY en çok ümit verici olumlu düşünmeyi sağladığı/hastalığın yan etkilerinin azalmasını istediği/hastalıkla savaşmak için; meme kanserli hastalar kanserle savaşa karşı vücudun direncini artırmak için kullanmaktadırlar. Hastaların TSY kullanımına doktorlarına danışarak başlama oranı ve TSY kullandığını hemşire ile paylaşım oranı oldukça düşüktür. Jinekolojik kanserli hastalar daha fazla el becerilerine yönelik, meme kanserli hastalar daha çok sosyalleşmeye yönelik rahatlama girişimlerini kullanmakta; jinekolojik kanserli hastalar daha çok bitkisel otlar, omega 3 ve anzer balı, meme kanserli hastalar meyve/sebze kullanımı gibi bitkisel ve besinsel yaklaşımları kullanmaktadırlar. Bu sonuçlar doğrultusunda; onkoloji alanında çalışan hemşire ve hekimlerin TSY etkileri, yan etkileri ve güvenilirliği konusunda bilgi sahibi olmaları ve kanıt düzeyi yüksek araştırma sonuçlarından yararlanmaları, hemşire ve hekimler tarafından jinekolojik ve meme kanseri tedavisi alan hastalara aralıklı olarak TSY kullanımına yönelik sorgulama ve danışmanlık yapılması gerekliliği önerilmektedir.

\section{BiLGi}

Bu çalışma, 5-6 Ekim 2017 tarihlerinde İzmit'te düzenlenen 2. Uluslararası Kadın Çocuk Sağlığı ve Eğitimi Kongresi'nde sözel bildiri olarak sunulmuştur.

\section{KAYNAKLAR}

1. National Center for Complementary and Integrative Health (2014). https://nccih.nih.gov/sites/nccam.nih.gov/files/CAM_Basics_What_Are_CAlHA_07-15-2014.2.pdf (Erişim tarihi: 31.07.2019).

2. Galbraith $\mathrm{N}$, et al. A systematic review of the traits and cognitions associated with use of and belief in complementary and alternative medicine (CAM). Psychology, Health \& Medicine 2018;23(7):854-69.

3. Tütüncü S. Geleneksel, alternatif ve tamamlayıcı tıp uygulamalarına genel bir bakış. In Tütüncü $S$, Etiler N, editors. Tibbin Alternatifi Olmaz! Geleneksel Alternatif ve Tamamlayici Tıp Uygulamaları. Ankara: Türk Tabipleri Birliği Yayınları; 2017. pp:1154.

4. Ilgaz A, Gözüm S. Tamamlayıcı sağlık yaklaşımlarının güvenilir kullanımı için sağlık okuryazarlığının önemi. DEUHFED 2016;9(2):67-77.

5. Başgöl Ş, Aslan E. Jinekolojik Kanserlerin tedavisinde tamamlayıcı ve alternative tedavi: Kanıta dayalı yaklaşım. Yıldırım Beyazıt Üniversitesi Sağlık Bilimleri Fakültesi Hemşirelik E-Dergisi 2014;2(3):51-62.

6. Can G, et al. Quality of life and complementary and alternative medicine use among cancer patients in Turkey. Eur J Oncol Nurs 2009;13(4):287-94. 
7. Sözeri E, Kahraman BB. Hasta ve hemşire perspektifinden tamamlayıcı sağlık yaklaşımları. Balıkesir Saglik Bil Derg 2016;5(1):3942.

8. Alternative medicine: guidelines for future research. BMC Complement Altern Med. 2014;14:46.

9. Yeşil $\mathrm{H}$, ve ark. Afyon Kocatepe Üniversitesi'nde meme kanseri tanısı ile takip edilmekte olan hastalarda tamamlayıcı ve alternatif tedavi kullanımı. Kocatepe Tıp Dergisi 2018;19:42-47.

10. Dedeoğlu B. Kanserli hastaların tamamlayıcı alternatif tedavileri kullanım durumları ve etkileyen faktörler. Trakya Üniversitesi Sağlık Bilimleri Enstitüsü Hemşirelik Anabilim Dalı. Yüksek Lisans Tezi. 2014. Edirne.

11. Kurt H, ve ark. Meme kanserli hastalarda tamamlayıcı/alternative tedavi kullanımı. Türk Onkoloji Dergisi 2013;28(1):10-5.

12. Duman M, Yüksekol ÖD, Ozan YD. Jinekolojik kanserli türk kadınlarının dini ve geleneksel uygulamaları. Jinekoloji-Obstetrik ve Neonatoloji Tıp Dergisi 2018;15(4):164-7.

13. Uğurluer G., ve ark. Ayaktan kemoterapi ünitesinde tedavi alan hastaların tamamlayıcı ve alternatif tıp uygulamalarına başvurma sıklı̆̆ ve nedenleri. Van Tıp Dergisi. 2007;14(3):68-73.

14. Algier LA, et al. The use of complementary and alternative (nonconventional) medicine in cancer patients in Turkey. Eur J Oncol Nurs 2005;9(2):138-46.

15. Amanak K, Karaöz B, Sevil Ü. Alternatif/tamamlayıcı tıp ve kadın sağlığı. TAF Prev. Med Bull 2013;12(4):441-8.

16. Öztürk R, Güleç Şatır D, Sevil Ü. Use of complementary and alternative medicine and attitudes in patients with gynaecological cancers. Gaziantep Med J 2016;22(3):141-7.

17. Nazik E, et al. Complementary and alternative medicine use by gynecologic oncology patients in Turkey. Asian Pacific J Cancer Prev 2012;13:21-25.

18. Yavuz $M$, ve ark. Meme kanserli hastaların tamamlayıc ve alternatif tedavi yöntemlerini kullanma durumlarının incelenmesi. Turkiye Klinikleri J Med Sci 2007;27:680-6.

19. Zeller $\mathrm{T}$, et al. Potential interactions of complementary and alternative medicine with cancer therapy in outpatients with gynecological cancer in a comprehensive cancer center. Cancer Res Clin Oncol 2013;139:357-65. doi: 10.1007/s00432-0121336-6.

20. Molassiotis A, et al. Complementary and alternative medicine use in patients with gynecological cancers in Europe. International Journal of Gynecological Cancer 2006;16(Suppl. 1):219-24. 